\title{
Surface modification of electrospun polyester nanofibers with cyclodextrin polymer for the removal of phenanthrene from aqueous solution
}

\author{
Fatma Kayaci, Zeynep Aytac, Tamer Uyar* \\ UNAM-Institute of Materials Science \& Nanotechnology, Bilkent University, Ankara 06800, Turkey
}

\section{H I G H L I G H T S}

- Electrospun PET nanofibers were surface modified with cyclodextrin polymer (CDP).

- Three different types of native $\mathrm{CD}(\alpha-$ $\mathrm{CD}, \beta-\mathrm{CD}$ and $\gamma-\mathrm{CD})$ were used to form CDP.

- Nanofibrous structure of PET mats was preserved after CDP surface modification.

- PET/CDP nanofibers have shown enhanced mechanical and thermal properties.

- PET/CDP nanofibers efficiently remove PAH (e.g. phenanthrene) from aqueous solution.

\section{A R T I C L E I N F O}

\section{Article history:}

Received 4 March 2013

Received in revised form 5 July 2013

Accepted 18 July 2013

Available online 25 July 2013

\section{Keywords:}

Electrospinning

Cyclodextrin polymer

Nanofibers

Polyester

Phenathrene

\section{G R A P H I C A L A B S T R A C T}

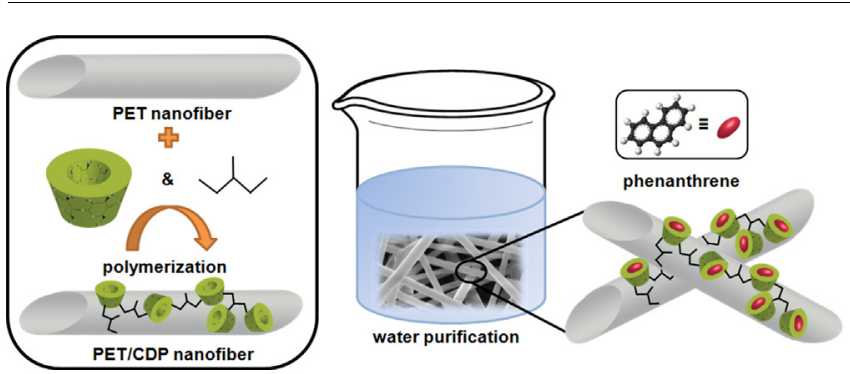

\begin{abstract}
A B S T R A C T
Surface modified electrospun polyester (PET) nanofibers with cyclodextrin polymer (CDP) were produced (PET/CDP). CDP formation onto electrospun PET nanofibers was achieved by polymerization between citric acid (CTR, crosslinking agent) and cyclodextrin (CD). Three different types of native CD $(\alpha-C D$, $\beta-C D$ and $\gamma-C D$ ) were used to form CDP. Water-insoluble crosslinked CDP coating was permanently adhered onto the PET nanofibers. SEM imaging indicated that the nanofibrous structure of PET mats was preserved after CDP surface modification process. PET/CDP nanofibers have shown rougher/irregular surface and larger fiber diameter when compared to untreated PET nanofibers. The surface analyses of PET/CDP nanofibers by XPS elucidated that CDP was present on the fiber surface. DMA analyses revealed the enhanced mechanical properties for PET/CDP where PET/CDP nanofibers have shown higher storage modulus and higher glass transition temperature compared to untreated PET nanofibers. The surface area of the PET/CDP nanofibers investigated by BET measurements showed slight decrease due to the presence of CDP coating compared to pristine PET nanofibers. Yet, it was observed that PET/CDP nanofibers were more efficient for the removal of phenanthrene as a model polycyclic aromatic hydrocarbon (PAH) from aqueous solution when compared to pristine PET nanofibers. Our findings suggested that PET/CDP nanofibers can be a very good candidate as a filter material for water purification and waste treatment owing to their very large surface area as well as inclusion complexation capability of surface associated CDP.

(C) 2013 Elsevier B.V. All rights reserved.
\end{abstract}

\footnotetext{
* Corresponding author. Tel.: +90 3122903571; fax: +90 3122664365.

E-mail addresses: tamer@unam.bilkent.edu.tr, uyar@unam.bilkent.edu.tr, tameruyar@gmail.com (T. Uyar).
}

\section{Introduction}

Electrospun nanofibers and their nanofibrous mats have demonstrated huge potential for filtration applications due to their 
high surface-to-volume ratio and nanoporous structure [1-3]. It has been reported that electrospun nanofibrous mats are quite effective for particulate separation [2,3], liquid filtration [1-3], waste vapor treatment [4,5] as well as desalination [6]. Electrospinning has advantage over conventional membrane production techniques, since variety of functional nanofibrous materials can be easily obtained in the form of nonwoven membranes which can be readily used as a filtering material [1-3]. In addition, the design flexibility of electrospun nanofibers for specific surface functionality can yield better adsorptive capacity and selective separation performance $[7,8]$.

Cyclodextrins (CD) have an outstanding capability to form inclusion complexes with variety of molecules through non-covalent host-guest interactions due to their toroid-shaped molecular structure [9]. CD are quite applicable in pharmacy, cosmetics, food, textiles, since $C D$ might enhance the solubility, stability, and bioavailability of the guest molecules [9-11]. In addition, CD have also potential to be used as a filtering material due to their ability to selectively form inclusion complexes with organic waste molecules $[12,13]$. CD are nontoxic and natural cyclic oligosaccharides derived from starch. The most common CD types are named as $\alpha-C D, \beta-C D$ and $\gamma$-CD having six, seven and eight glucopyranose units, respectively. These CD have the same cavity depth which is $\sim 7.8 \AA$, while the diameter of the cavity for $\alpha-C D, \beta-C D, \gamma-C D$ are $\sim 6,8$, and $10 \AA$, respectively [9]. Hence, $\alpha-C D, \beta-C D$ and $\gamma$-CD show different capabilities for the inclusion complex formation with the same guest molecule, because the formation of inclusion complex primarily depends on the size match and binding forces between CD cavity and guest molecule [14].

$\mathrm{CD}$ are water soluble, therefore, they cannot be used directly as a filtering material for the removal of organic pollutants from water and wastewater. So, crosslinked and water-insoluble CD based polymers were synthesized for capturing organic pollutants from the surroundings [13]. Alternatively, CD molecules could be permanently immobilized by chemically grafting onto polymeric fibers [15-18], or the surface of the fibers could be modified by crosslinked CD polymer [19-21] for filtration purposes or delivery of additives. Moreover, in order to combine the complex formation capability of $C D$ along with very high surface area of the electrospun nanofibrous mat, surface functionalization of electrospun nanofibers with $C D$ would be quite interesting for designing efficient filtering materials. In fact, in our recent studies we have incorporated $C D$ into nanofibers by electrospinning of physical mixture of polymer/CD solution [4,22,23]. Although most of the CD molecules were buried inside the fiber matrix, we observed that some $C D$ molecules were present on the fiber surface, and these surface associated $\mathrm{CD}$ molecules were effective for the removal of organic molecules from liquid media [22,23] and vapor phase [4]. However, CD molecules were physically attached to the fiber surface; so, the leaching of $C D$ molecules from the fiber surface during filtration especially in the liquid media was inevitable. Consequently, permanent $C D$ modification onto electrospun nanofibers would be ideal for designing novel filtering materials for water purification and wastewater treatment. Even though surface modifications of fibers and nonwoven fabrics by CD grafting [15-17] or coating with crosslinked CD polymer [19-21,24] were reported, to the best of our knowledge, the surface modification of electrospun polymeric nanofibers with crosslinked CD polymer was not reported previously.

In this study, we have achieved the surface modification of the electrospun polyester (PET) nanofibers with cyclodextrin polymer (CDP). Water-insoluble and crosslinked CDP coating onto PET nanofibers was formed by the polymerization reaction between $\mathrm{CD}$ and crosslinking agent (citric acid). For a comparative study, three types of $C D(\alpha-C D, \beta-C D$ and $\gamma-C D)$ were used in order to form CDP coating onto PET nanofibers. The morphological, surface, thermal and mechanical properties of surface modified electrospun PET nanofibers with CDP (PET/CDP) were examined. The filtration performance of the PET/CDP nanofibrous mats was investigated by removal of a model polycyclic aromatic hydrocarbon (phenanthrene) from aqueous solution.

\section{Materials and methods}

\subsection{Materials}

Polyethylene terephthalate (PET) chips were gifts from Korteks (Bursa, Turkey). Dichloromethane (DCM, Sigma Aldrich, extra pure), trifluoroacetic acid (TFA, Alfa Aesar, 99\%), acetonitrile chromasol V (Sigma Aldrich, 99.9\%), citric acid monohydrate-gritty puriss (CTR, Sigma Aldrich, 99.5-100.5\%), sodium hypophosphite hydrate (SHPI, Sigma Aldrich), phenanthrene (Sigma Aldrich, 98\%), and cyclodextrins $(\alpha-C D, \beta-C D$ and $\gamma-C D$, Wacker Chemie AG) were purchased and used as-received without any purification. Distilled water was from Millipore Milli-Q ultrapure water system.

\subsection{Preparation of polymer solution and electrospinning of nanofibers}

First, different polymer concentrations were used for the electrospinning of PET solution in order to obtain uniform and bead-free PET nanofibers, and $22.5 \%(\mathrm{w} / \mathrm{v})$ polymer concentration was found to be the optimal. Therefore, 22.5\% (w/v) PET was dissolved in TFA/DCM (50/50, v/v), and the resulting solution was loaded into $5 \mathrm{~mL}$ syringe fitted with a metallic needle having an inner diameter of $0.8 \mathrm{~mm}$. Then, the syringe was placed horizontally on the syringe pump (KD Scientific, KDS 101). The polymer solution was pumped with $1 \mathrm{~mL} / \mathrm{h}$ flow rate during the electrospinning, and the distance was set to $12 \mathrm{~cm}$ between needle tip and grounded stationary cylindrical metal collector (height: $15 \mathrm{~cm}$, diameter: $9 \mathrm{~cm}$ ) covered with a piece of aluminum foil. A voltage of $15 \mathrm{kV}$ was applied for the electrospinning by using high voltage power supply (Matsusada, AU Series). The electrospinning process was carried out at $24.5^{\circ} \mathrm{C}$ and $17 \%$ relative humidity in an enclosed Plexiglas box.

\subsection{Formation of cyclodextrin polymer (CDP) onto PET nanofibers}

$10 \%(w / v)$ of $\alpha-C D, \beta-C D$ and $\gamma-C D$ was mixed individually in $150 \mathrm{~mL}$ aqueous solution at $50{ }^{\circ} \mathrm{C}$, and then, $10 \%(\mathrm{w} / \mathrm{v}) \mathrm{CTR}$ as a crosslinking agent and $1.2 \%(\mathrm{w} / \mathrm{v})$ SHPI as a catalyst were added to each CD solution separately, and stirred for $30 \mathrm{~min}$ at $50^{\circ} \mathrm{C}$. After all reactants were dissolved in aqueous solution, three rectangular shaped (about $12 \mathrm{~cm} \times 11 \mathrm{~cm}, 0.4 \mathrm{~g}$ ) electrospun PET nanofibrous mats were immersed into the each resulting solution and kept for $3 \mathrm{~h}$ at $50^{\circ} \mathrm{C}$. Then these nanofibrous mats were dried at $105^{\circ} \mathrm{C}$ for $10 \mathrm{~min}$, and then cured at $180^{\circ} \mathrm{C}$ for $7 \mathrm{~min}$ for the CDP formation onto PET nanofibers. Finally the resulting nanofibrous mats were washed two times with warm water $\left(40^{\circ} \mathrm{C}\right)$ for the removal of unreacted $C D$ and CTR if any present, and then dried at $105^{\circ} \mathrm{C}$ for $7 \mathrm{~min}$. In order to make clear identification, CDP modified PET nanofibers are named as PET $/ \alpha-C D P, P E T / \beta-C D P$ and PET $/ \gamma-C D P$ according the type of $C D$ used $(\alpha-C D, \beta-C D$ and $\gamma-C D)$.

\subsection{Characterizations and measurements}

The morphology and the diameter of the PET and PET/CDP nanofibers were examined by using scanning electron microscope (SEM, FEI-Quanta 200 FEG). The nanofibers were coated with $5 \mathrm{~nm}$ $\mathrm{Au} / \mathrm{Pd}$ prior to SEM analysis. To report the average fiber diameter (AFD) of the nanofibers, around 100 fibers of each sample were measured. 
The chemical surface analyses of the PET and PET/CDP nanofibers were carried out by means of high-performance X-ray photoelectron spectroscopy (XPS,Thermo Scientific). XPS data were taken by a flood gun charge neutralizer system equipped with a monochromated $\mathrm{Al} \mathrm{K-} \alpha \mathrm{X}$-ray source $(h v=1486.6 \mathrm{eV})$. In order to determine the surface elemental compositions wide energy survey scans of the nanofibers were acquired over the $0-1360 \mathrm{eV}$ binding energy range, at pass energy of $150 \mathrm{eV}$ with energy step size of $1 \mathrm{eV}$ from $400 \mu \mathrm{m}$ diameter circular spot in nanofibers. The high resolution spectra were recorded for $\mathrm{O} 1 \mathrm{~s}$ region at pass energy of $30 \mathrm{eV}$ and with energy steps of $0.1 \mathrm{eV}$ in order to analyze the bonding states.

The thermal analyses of the samples were investigated by using thermogravimetric analyzer (TGA, TA Q500). TGA measurements were carried out under the nitrogen atmosphere, and the samples were heated from room temperature to $600^{\circ} \mathrm{C}$ (nanofibers) or $500^{\circ} \mathrm{C}\left(\mathrm{CTR}\right.$ and CD) at a constant heating rate of $20^{\circ} \mathrm{C} / \mathrm{min}$.

The dynamic thermo mechanical performance of the nanofibrous mats was determined using a dynamic mechanical analyzer (DMA, TA Q800) in tension film clamp at a constant frequency of $1 \mathrm{~Hz}$. The samples having size of $10 \mathrm{~mm}$ (gap) $\times \sim 3 \mathrm{~mm}$ (width) $\times \sim 0.12 \mathrm{~mm}$ (thickness) were measured. The amplitude of $20 \mu \mathrm{m}$ was applied. The storage modulus and loss tangent $(\tan \delta)$ of the nanofibrous mats were recorded in the range of $50-150^{\circ} \mathrm{C}$ at a heating rate of $3^{\circ} \mathrm{C} / \mathrm{min}$.

The surface area, average pore diameter (mesopore) and cumulative pore volume of the electrospun PET and PET/CDP nanofibers were examined using Brunauer-Emmett-Teller (BET) surface area analyzer (Quantachrome, IQ-C model) with low-temperature $(77.35 \mathrm{~K})$ nitrogen adsorption isotherms measured over a wide range of relative pressures from 0.00 to 1.00 . Prior to measurement, the each sample was placed in a $9 \mathrm{~mm}$ cell and degassed at $323.15 \mathrm{~K}$ for $12 \mathrm{~h}$ in the degas pot of the adsorption analyzer. The surface area of the samples was determined with multipoint BET method. On the other hand, density functional theory (DFT) was used to determine cumulative pore volume.

The molecular filtration performance of the resulting nanofibrous mats for water purification was tested using phenanthrene as a model polycyclic aromatic hydrocarbon (PAH). First, phenanthrene was dissolved in acetonitrile, and then $10 \mu \mathrm{L}$ of this solution was dropped in $50 \mathrm{~mL}$ pure water in order to obtain $1.8 \mathrm{ppm}$ phenanthrene aqueous solution. Square shaped of PET, PET $/ \alpha-C D P$, $\mathrm{PET} / \beta-\mathrm{CDP}$ and PET $/ \gamma$-CDP nanofibrous mats $(6 \mathrm{~cm} \times 6 \mathrm{~cm})$ were immersed individually in the $1.8 \mathrm{ppm}$ phenanthrene aqueous solution $(50 \mathrm{~mL})$. We kept the size of the mats identical; however, the weight of each PET/CDP mat was about $0.38 \mathrm{~g}$, while that of PET nanofibrous mat was about $0.63 \mathrm{~g}$ due to difference in the thickness of the mats, since the nanofibers were collected in different times for each sample. It is quite difficult to keep the thickness of the electrospun mats even identical time. For filtration measurements, $0.5 \mathrm{~mL}$ of each solution was withdrawn to measure phenanthrene concentration in the solution and replenished with same amount of water at pre-determined time intervals. The phenanthrene filtration performance from aqueous solution by PET and PET/CDP nanofibrous mats was investigated by high performance liquid chromatography (HPLC, Agilient 1200 series) equipped with VWD UV detector. The column was Agilient C18, $150 \mathrm{~mm} \times 4.6 \mathrm{~mm}(5 \mu \mathrm{m}$ pores) and the detection was accomplished at $254 \mathrm{~nm}$. Mobile phase, flow rate, injection volume and total run time were acetonitrile (100\%), $0.6 \mathrm{~mL} / \mathrm{min}, 10 \mu \mathrm{L}$ and $5 \mathrm{~min}$, respectively. As a result, the amount of phenanthrene remaining in the solution was determined from the area of phenanthrene peak observed in HPLC chromatograms. Then the calibration curve was prepared by using phenanthrene solutions (1.8 ppm, $0.9 \mathrm{ppm}, 0.45 \mathrm{ppm}, 0.23 \mathrm{ppm}$, $0.12 \mathrm{ppm}$ ) and $R^{2}$ was calculated as 0.985 . The peak area under curves was converted to concentration ( $\mathrm{ppm}$ ) according to the calibration curve. This experiment was repeated three times for each sample. The results were reported as the average \pm standard deviation of phenanthrene concentration remaining in the solution.

\section{Results and discussion}

\subsection{The CDP formation onto electrospun PET nanofibers}

In this study, polyester (PET) nanofibers were obtained by electrospinning of $22.5 \%$ (w/v) PET solution in TFA/DCM (50/50, $\mathrm{v} / \mathrm{v}$ ), as it is schematically given in Fig. 1a. The chemical reaction cannot occur between cyclodextrin (CD)/citric acid (CTR) and PET nanofibers directly, since PET, a polymer based on terephtalic acid and ethylene glycol, does not contain free reactive groups. Therefore, we modified the surface of the electrospun PET nanofibers through the polymerization reaction between CTR and CD $[21,24,25]$. Water-insoluble cyclodextrin polymer (CDP) network was formed by the crosslinking reaction between $C D$ and CTR [26]. Three different types of native $C D(\alpha-C D, \beta-C D$ and $\gamma-C D)$ were used to form $\alpha$-CDP, $\beta$-CDP and $\gamma$-CDP. Initially, electrospun PET nanofibrous mats were impregnated in a solution of $C D, C T R$, and sodium hypophosphite (SHPI, catalyst), and then dried, followed by curing at $180^{\circ} \mathrm{C}$ for $7 \mathrm{~min}$. CTR turn into a cyclic anhydride intermediate by thermal dehydration at elevated temperature, and then hydroxyl groups of $C D$ reacted with the carboxyl groups of citric acid [25]. The mechanism of the CDP formation is schematically described in Fig. 1b. CDP was formed as a three-dimensional network structure onto PET nanofibers. Due to crosslinked structure, the CDP is stable and water-insoluble [27,28]. Thereby, surface modification of CDP onto PET nanofibers is permanent and can resist to leaching or washing process [21,24,25,29]. The resulting CDP having the essential structural characteristics of CD was not covalently fixed to the PET nanofibers, but it was physically adhered or was entangled onto PET fiber matrix [21,24]. CDP modified PET nanofibers are called as PET/CDP. The representative photograph of the easily handled free-standing PET/CDP nanofibrous mat and the schematic representation of PET/CDP nanofibers are given in Fig. 1c.

\subsection{Morphological characterization of the nanofibers}

Scanning electron microscope (SEM) analysis was performed to investigate any morphological changes after the surface modification of PET nanofibers with CDP. Fig. 2 shows the representative SEM images and average fiber diameter (AFD) of unmodified PET, PET $/ \alpha-C D P, P E T / \beta-C D P$ and PET $/ \gamma$-CDP nanofibers. As clearly seen from SEM images, the surface morphologies of all three PET/CDP nanofibers were obviously different from the unmodified PET nanofibers. The surface of the unmodified PET nanofibers was smooth and uniform, whereas the surfaces of the PET/CDP nanofibers appear rough possibly due to CDP layer onto nanofibers. The rough surface has also been reported for cotton fabrics grafted with glycidyl methacrylate/ $\beta-C D$ [17] and hydroxypropylCD grafted woven PET vascular prosthesis [20,21]. Moreover, surface irregularities at certain points were also observed in the SEM images of PET/CDP nanofibers. Similar morphological observations were also reported for cotton fabric grafted with monochlorotriazinyl- $\beta-\mathrm{CD} /$ butylacrylate [30]. In brief, the rough and irregular surface of modified PET nanofibers suggested the successful attachment of CDP onto PET nanofibers. More importantly, CDP surface modification process did not deform the fibrous structure of PET as clearly seen from the SEM images. The unmodified PET nanofibers have $870 \pm 260 \mathrm{~nm}$ of AFD, while the AFD of PET $/ \alpha$ CDP, PET $/ \beta-C D P$ and PET $/ \gamma$-CDP were measured as $1200 \pm 350$, $1290 \pm 490$ and $950 \pm 270 \mathrm{~nm}$, respectively. The increase in the AFD 
a.

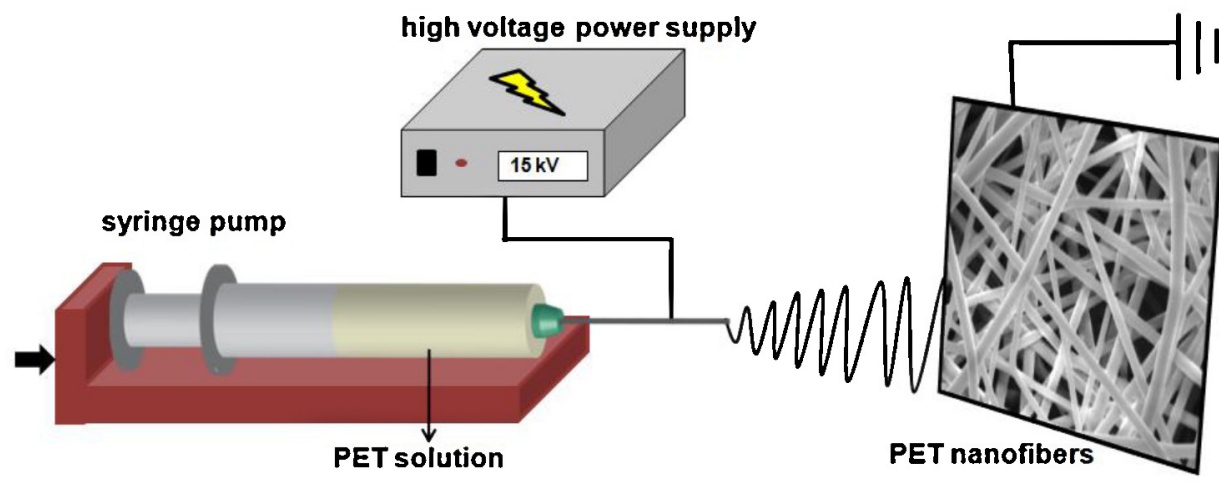

b.
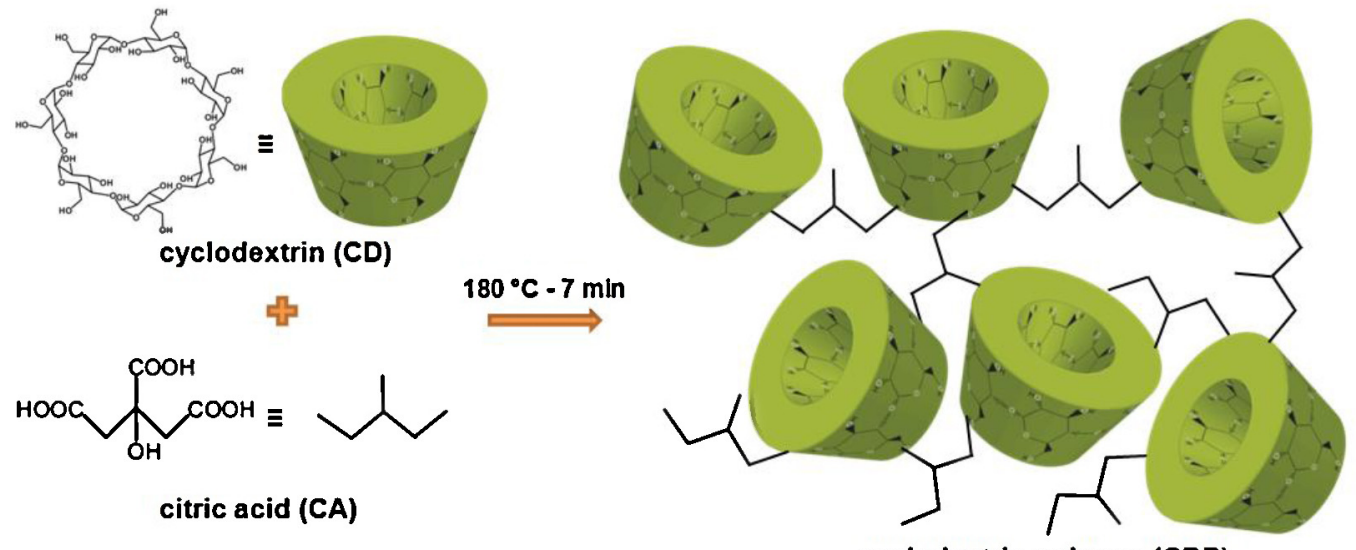

cyclodextrin polymer (CDP)

c.

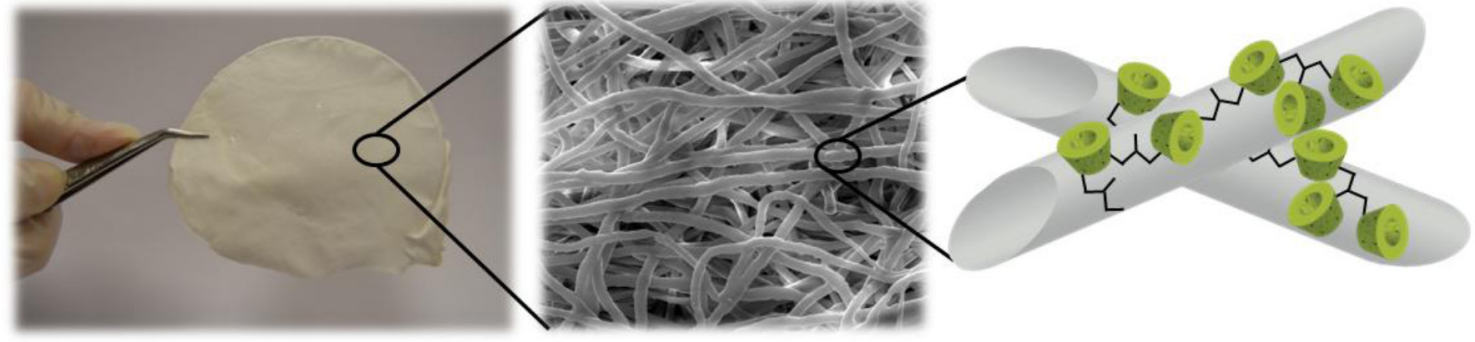

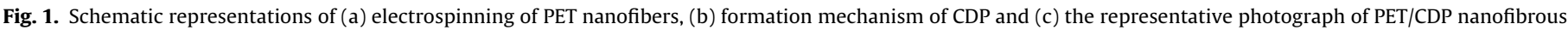
mat and its SEM image and schematic representation of PET/CDP nanofibers.

of PET/CDP nanofibers compared to unmodified PET nanofibers could be due to the coating of the CDP onto PET nanofibers. Additionally, slight swelling of nanofibers during the modification process might also have resulted in fiber diameter increase.

\subsection{Surface chemical characterization of the nanofibers}

The surface chemical characterization of PET/CDP nanofibers was performed by using X-ray photoelectron spectroscopy (XPS) in order to further demonstrate the coating of CDP onto PET nanofibers. Table 1 shows elementary compositions based on wide energy survey spectra of the unmodified PET nanofibers and PET/CDP nanofibers. The survey spectra comprising two peaks: C

Table 1

Atomic concentrations generated from XPS wide energy survey scans.

\begin{tabular}{lll}
\hline Samples & $C(\%)$ & $\mathrm{O}(\%)$ \\
\hline PET & 72.21 & 27.79 \\
PET $/ \alpha-C D P$ & 64.92 & 35.08 \\
PET $/ \beta-C D P$ & 61.29 & 38.71 \\
PET $/ \gamma$-CDP & 67.89 & 34.31 \\
\hline
\end{tabular}

$1 \mathrm{~s}$ and $\mathrm{O} 1 \mathrm{~s}$ are consistent with the molecular structure of PET and CDP. The XPS data showed that the unmodified PET nanofibers have C 1s:O 1s=72.21:27.79 (\%) which is in full agreement with the literature [31]. Oxygen content on the surface of the samples was increased with the modification of CDP onto PET nanofibers. Thus, the appearance of higher oxygen content provides an evidence of the presence of CDP on the PET fiber surfaces.

High-energy resolution 0 1s XPS spectra were also recorded to get more detailed chemical state information about surface chemistry of the PET/CDP nanofibers. Fig. 3 shows the normalized $O 1 \mathrm{~s}$ spectra of PET and PET $/ \gamma$-CDP nanofibers. The assigned different components within these spectra and their individualized fitting parameters (peak binding energy and \% area ratio) are also given in Table 2. Since the $O 1 \mathrm{~s}$ spectra of all PET/CDP nanofibers (PET $/ \alpha-$ CDP, PET $/ \beta-C D P$ and PET $/ \gamma-C D P)$ are similar to each other, those XPS data acquired for PET $/ \alpha-C D P$ and PET $/ \beta$-CDP nanofibers were not given. The $\mathrm{O} 1 \mathrm{~s}$ spectrum of unmodified PET nanofibers clearly represent the two types of oxygen atoms within the ester groups; $\pi$-bonded oxygen $\left(\mathrm{C}=\mathrm{O}^{*}\right)$ and $\sigma$-bonded oxygen $\left(\mathrm{C}-\mathrm{O}^{*}\right)$ at binding energies of 531.54 and $533.12 \mathrm{eV}$, respectively [32-35]. The ratio of these peaks is 56.2:42.1, which is in reasonable agreement with the theoretical ratio of 50:50 [36]. In addition to these expected $01 \mathrm{~s}$ 

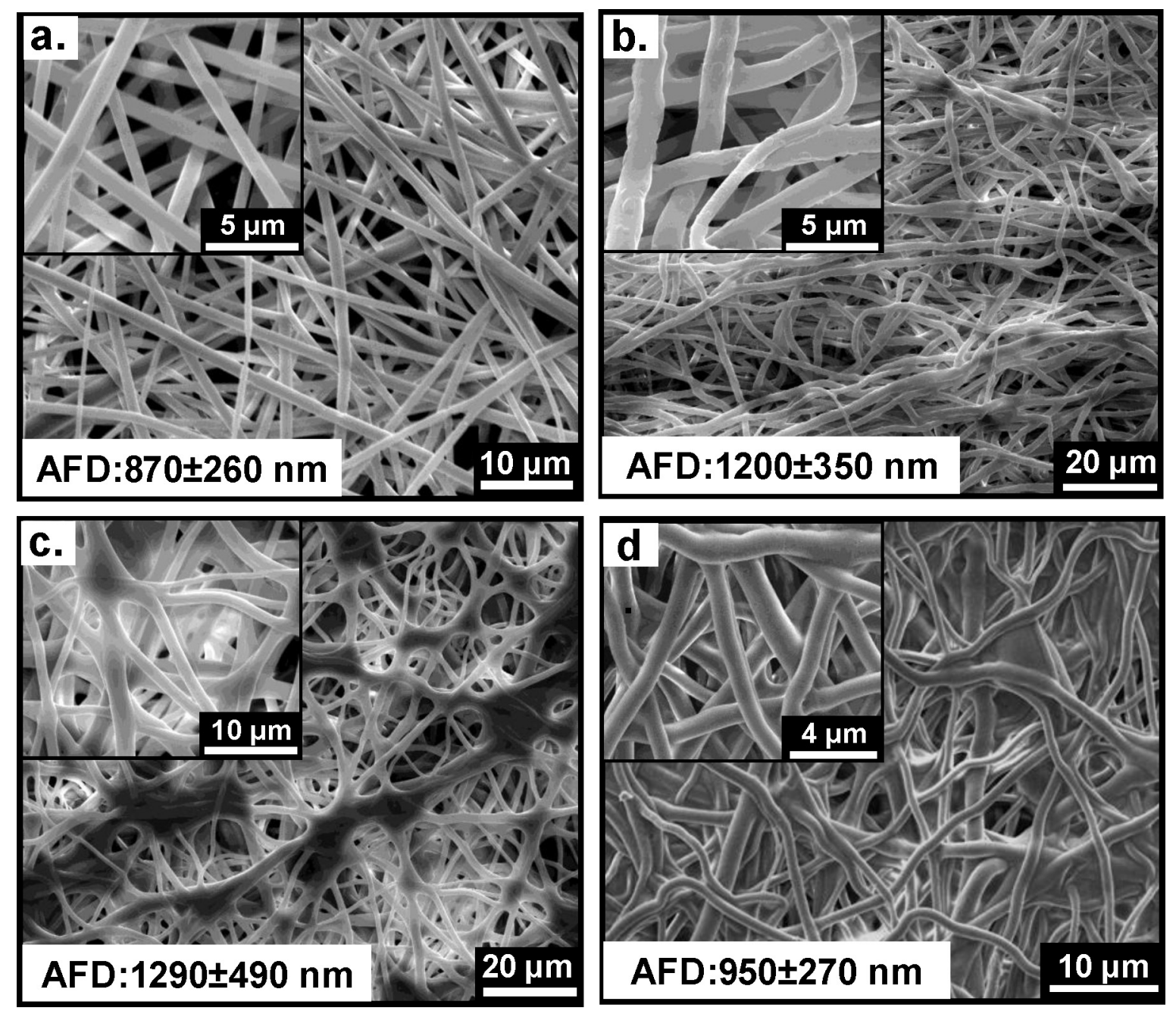

Fig. 2. Representative SEM images and AFD of (a) PET, (b) PET/ $\alpha$-CDP, (c) PET/ $\beta$-CDP and (d) PET/ $\gamma$-CDP nanofibers. The insets show higher magnification images.

peaks, PET nanofibers have a very small peak situated at $534.52 \mathrm{eV}$ assigned to adsorbed water [32]. After the CDP modification on the surface of PET nanofibers, the contribution of additional $\mathrm{O} 1 \mathrm{~s}$ fitting peak at 532.35 related to aliphatic $\mathrm{C}-\mathrm{O}^{*} \mathrm{H}$ came into view. The appearance of $\mathrm{C}-\mathrm{O}^{*} \mathrm{H}$ component belongs to hydroxyl groups and carboxyl groups of CDP elucidated the successful surface modification of PET nanofibers with CDP. Moreover, as it was expected, CDP modification onto PET nanofibers resulted in significant increase of relative XPS signal intensity in the $\mathrm{O} 1 \mathrm{~s}$ peak situated at $533.06 \mathrm{eV}$ assigned to $\sigma$-bonded oxygen $\left(\mathrm{C}-\mathrm{O}^{*}\right)$ compared with $\pi$-bonded oxygen $\left(\mathrm{C}=\mathrm{O}^{*}\right)$ located at $532.35 \mathrm{eV}$. In brief, there are three different components $\left(\mathrm{C}-\mathrm{O}^{*}, \mathrm{C}=\mathrm{O}^{*}\right.$ and $\left.\mathrm{C}-\mathrm{O}^{*} \mathrm{H}\right)$ for $\mathrm{O} 1 \mathrm{~s}$ high-resolution spectra of the PET/CDP nanofibers. The increase in oxygen content of PET/CDP nanofibers compared to unmodified PET nanofibers was
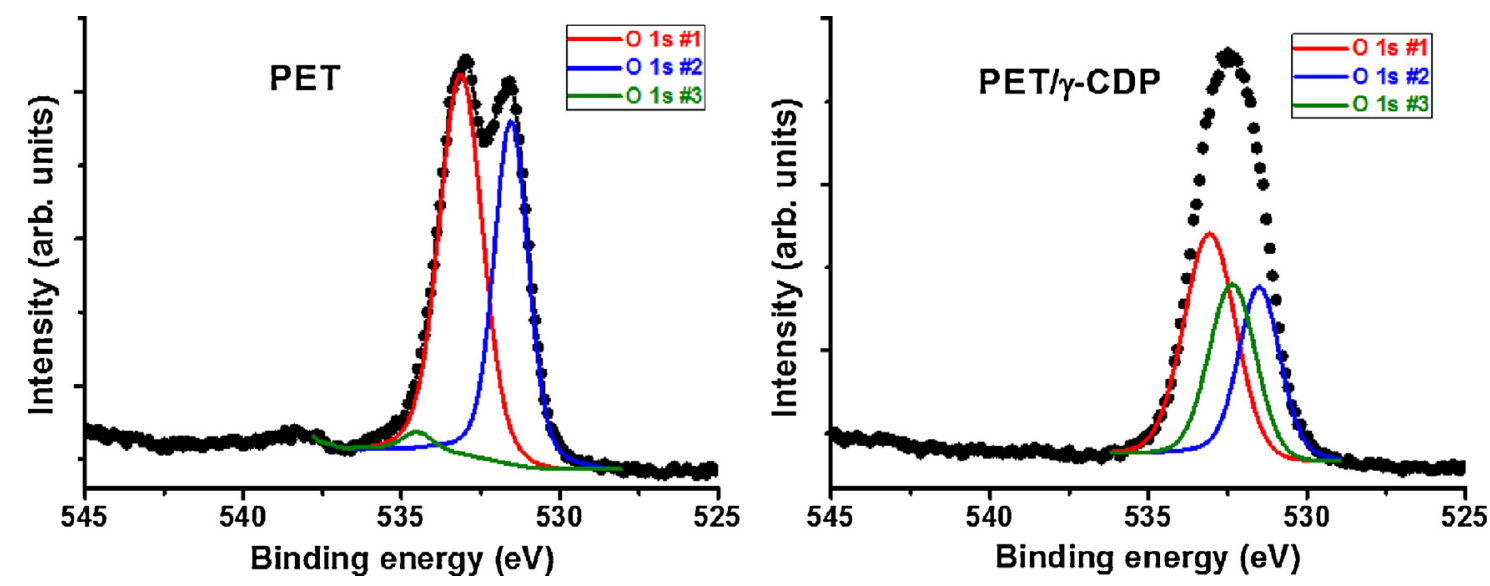

Fig. 3. High resolution 01 s XPS spectra of PET and PET/ $\gamma$-CDP nanofibers. 

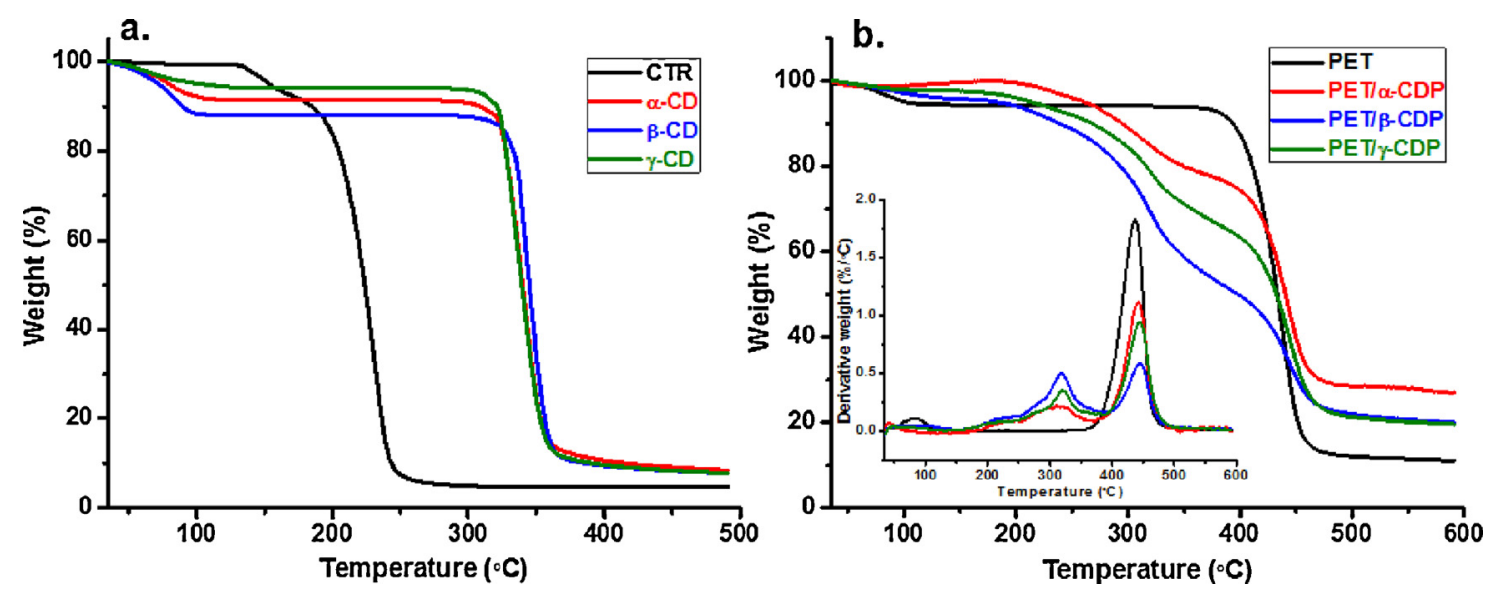

Fig. 4. (a) TGA thermograms of CTR and three CD types ( $\alpha-C D, \beta-C D$ and $\gamma-C D$ ), (b) TGA and derivative TGA (inset) thermograms of nanofibers.

especially due to the appearance of $\mathrm{C}-\mathrm{O}^{*} \mathrm{H}$ for the samples. The presence of CDP on the fiber surface is quite important in terms of the filtration application of PET/CDP nanofibrous mats [4,22,23].

\subsection{Thermal characterization of the nanofibers}

The thermal characteristics of the PET/CDP samples were investigated by using thermogravimetric analyzer (TGA). In Fig. 4, the TGA thermograms of CTR and CD ( $\alpha-C D, \beta-C D$ and $\gamma-C D)$ (Fig. $4 a)$, and unmodified PET and PET/CDP nanofibers (Fig. 4b) are given. Moreover, the derivative TGA thermograms of nanofibers are also shown as inset in Fig. 4b. The weight loss for CTR started at around $130^{\circ} \mathrm{C}$, and CTR completely degraded before $250^{\circ} \mathrm{C}$. TGA thermograms of $C D(\alpha-C D, \beta-C D$ and $\gamma-C D)$ presented an initial weight loss below $100^{\circ} \mathrm{C}$ and a major weight loss between 300 and $350{ }^{\circ} \mathrm{C}$ which correspond to the water loss and main degradation of $C D$, respectively [37]. The main degradation of PET nanofibers occurred between 375 and $475^{\circ} \mathrm{C}$. For the PET/CDP nanofibers two major weight losses were recorded between $200-350^{\circ} \mathrm{C}$ and $375-475^{\circ} \mathrm{C}$ which correspond to main thermal degradation of CDP and PET, respectively. The \% weight loss between 200 and $350{ }^{\circ} \mathrm{C}$ corresponding to CDP in the PET/CDP nanofibers was $23 \%, 44 \%$ and $32 \%$ for PET $/ \alpha-C D P, P E T / \beta-C D P$ and PET $/ \gamma$-CDP nanofibers, respectively, suggesting that the amount of CDP coating onto PET nanofibers was on the order of $\beta$-CDP $>\gamma$-CDP $>\alpha$-CDP. When the derivative weight $\%$ loss was analyzed (Fig. 4b), it was observed that the peak point for the unmodified PET $\left(\sim 437^{\circ} \mathrm{C}\right)$ shifted slightly to higher temperature $\left(\sim 445^{\circ} \mathrm{C}\right)$ for the PET/CDP nanofibers. This indicated that the modification of PET nanofibers with CDP resulted in slightly higher thermal stability due to more energy requirement for decomposition of these samples having crosslinked structure. The increased thermal stability has been also observed for $C D$ grafted polyamide 6 fabrics [38]. Moreover, the char yield was higher for PET/CDP nanofibers when compared to unmodified PET nanofibers possibly owing to the crosslinked CDP structure providing higher carbon residue upon burning.

Table 2

Fitting parameters of the O 1s XPS spectra of PET and PET $/ \gamma$-CDP nanofibers.

\begin{tabular}{|c|c|c|c|c|}
\hline Samples & Fitting peaks & Bonds & $\begin{array}{l}\text { Peak binding } \\
\text { energy }\end{array}$ & $\begin{array}{l}\text { Area ratio } \\
(\%)\end{array}$ \\
\hline \multirow[t]{3}{*}{ PET } & O 1s \#1 & $\mathrm{C}-\mathrm{O}^{*}$ & 533.12 & 56.2 \\
\hline & O 1s \#2 & $\mathrm{C}=\mathrm{O}^{*}$ & 531.54 & 42.1 \\
\hline & O 1s \#3 & Adsorbed $\mathrm{H}_{2} \mathrm{O}$ & 534.52 & 1.7 \\
\hline \multirow[t]{3}{*}{$\mathrm{PET} / \gamma-\mathrm{CDP}$} & O 1s \#1 & $\mathrm{C}-\mathrm{O}^{*}$ & 533.06 & 42.5 \\
\hline & O 1s \#2 & $\mathrm{C}=\mathrm{O}^{*}$ & 531.5 & 27.7 \\
\hline & O 1s \#3 & $\mathrm{C}-\mathrm{O}^{*} \mathrm{H}$ & 532.35 & 29.8 \\
\hline
\end{tabular}

\subsection{Mechanical characterization of the nanofibers}

Dynamic mechanical analyzer (DMA) was used to investigate the effect of CDP modification on the thermomechanical properties of the PET nanofibers. The storage modulus and loss tangent $(\tan \delta)$ of the unmodified PET and PET/CDP nanofibrous mats were recorded up to $150^{\circ} \mathrm{C}$ (Fig. 5). The storage modulus of the samples decreased with increasing temperature due to the transition from glassy state to rubbery state. It was observed that storage modulus of the PET/CDP nanofibrous mats was much higher than the unmodified PET nanofibers possibly due to stiffening effect of crosslinked CDP coating. Since the transferred stress for PET nanofibers was shared by CDP coating, the storage modulus of PET nanofibers enhanced with CDP modification. Moreover, for CDP modified nanofibers, $\tan \delta$ peak shifted to the higher temperature region indicating that the glass transition temperature $\left(T_{\mathrm{g}}\right)$ for these nanofibers was higher when compared to unmodified PET nanofibers. The $T_{\mathrm{g}}$ value of PET nanofibers was $92^{\circ} \mathrm{C}$, while the $T_{\mathrm{g}}$ values of PET/CDP nanofibers were recorded as 109,112 and $113^{\circ} \mathrm{C}$ for PET $/ \alpha-C D P, P E T / \beta-C D P$ and PET $/ \gamma$-CDP nanofibers, respectively. This result suggested that the mobilization of PET macromolecular chains were affected and the segmental motion of PET chains were hindered by CDP modification. Furthermore, broader $\tan \delta$ peaks observed for PET/CDP nanofibers which can be originated from two $T_{\mathrm{g}}$ values correspond to not only PET, but also CDP [39].

\subsection{Surface area of the nanofibers}

The surface area, average pore diameter and cumulative pore volume of the PET and PET/CDP nanofibers were investigated by BET measurements and the data is summarized in Table 3 . The results indicated that the multipoint BET surface area of electrospun PET nanofibers is $6.03 \mathrm{~m}^{2} / \mathrm{g}$. The surface area decreased to $1.56,0.57$ and $0.72 \mathrm{~m}^{2} / \mathrm{g}$ for PET/ $\alpha$-CDP, PET $/ \beta$-CDP and PET $/ \gamma-C D P$ nanofibers, respectively. As mentioned in SEM characterization, the surface modification of the PET nanofibers with CDP resulted in the irregularities on the fiber surfaces and AFD for these samples were

Table 3

Surface area, average pore diameter and cumulative pore volume data of the nanofibers.

\begin{tabular}{llll}
\hline Samples & $\begin{array}{l}\text { Multipoint BET } \\
\text { surface area }\left(\mathrm{m}^{2} / \mathrm{g}\right)\end{array}$ & $\begin{array}{l}\text { Average pore } \\
\text { diameter }(\mathrm{nm})\end{array}$ & $\begin{array}{l}\text { DFT cumulative } \\
\text { pore volume }(\mathrm{cc} / \mathrm{g})\end{array}$ \\
\hline $\mathrm{PET}$ & 6.03 & 15.3 & $1.03 \times 10^{-2}$ \\
$\mathrm{PET} / \alpha-\mathrm{CDP}$ & 1.56 & 12.4 & $3.22 \times 10^{-3}$ \\
$\mathrm{PET} / \beta-\mathrm{CDP}$ & 0.57 & 13.6 & $1.28 \times 10^{-3}$ \\
$\mathrm{PET} / \gamma$-CDP & 0.72 & 14.0 & $1.05 \times 10^{-3}$ \\
\hline
\end{tabular}



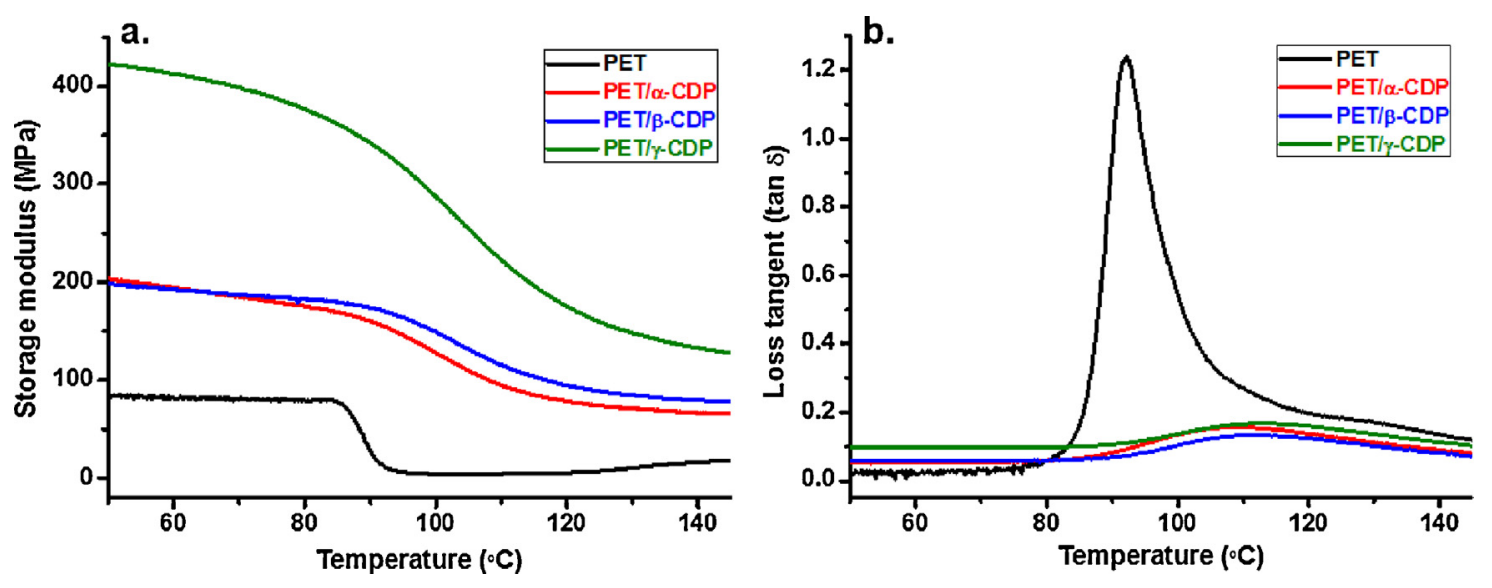

Fig. 5. DMA thermograms of nanofibrous mats (a) storage modulus and (b) loss tangent ( $\tan \delta$ ).

increased as well, and therefore, the surface area of the PET/CDP nanofibers were decreased. The surface irregularities of nanofibers such as crosslinked CDP coating are clearly observed especially in the SEM images of the PET $/ \beta-C D P$ and PET $/ \gamma$-CDP nanofibers (Fig. 2c and d). Hence, the surface area of PET $/ \beta-C D P$ and PET $/ \gamma-$ CDP nanofibers was less than that of PET $/ \alpha$-CDP. Moreover, since PET $/ \beta$-CDP has the largest AFD among the samples (Fig. $2 c$ ), the surface area of PET $/ \beta$-CDP nanofibers was slightly less than PET $/ \gamma-C D P$ nanofibers. It is well known that the AFD have great effect on the surface area of fibers [40]. We have also calculated the mesopore structure (average pore diameter and cumulative pore volume) of the PET and PET/CDP nanofibers. It was observed that, the average pore diameter and cumulative pore volume determined by density functional theory (DFT) also decreased after surface modification of the PET nanofibers possibly due to the crosslinked CDP coating onto nanofiber surface which resulted in surface irregularities. In short, the surface area of the PET/CDP nanofibers was decreased due to the presence of CDP coating compared to pristine PET nanofibers, nevertheless, as discussed in the following section, PET/CDP nanofibers were more efficient for the removal of the phenanthrene from aqueous solution when compared to pristine PET nanofibers.

\subsection{Molecular filtration performance of the nanofibers for water purification}

The molecular filtration capability of PET and PET/CDP nanofibrous mats has been tested using a phenanthrene as a model polycyclic aromatic hydrocarbon (PAH). Phenanthrene is a common pollutant and can form inclusion complexes with CD [12,41,42]. Fig. 6 summarizes the cumulative \% decrease of phenanthrene concentration over time when PET and PET/CDP mats have been kept in aqueous solution of phenanthrene. As seen in Fig. 6, the concentration of phenanthrene in the aqueous solution decreased within the contact time. The adsorption of phenanthrene by PET nanofibers for the first $2 \mathrm{~h}$ was observed, and then the concentration of phenanthrene slightly decreased over time. On the other hand, the decrease of phenanthrene concentration for PET/CDP mats was more significant. Although less amount of PET/CDP nanofibers were used compared to PET nanofibers for filtration test, the removal efficiency of the phenanthrene from its aqueous solution was better when PET/CDP nanofibers were used. Water-insoluble CDP can be very effective in removal of many organic pollutants from aqueous media, since CD cavity is capable of forming inclusion complexes with a wide variety of organic molecules [9-11,13,18,22,28]. Therefore, the surface modification of electrospun PET nanofibers with CDP increased the efficiency of filtration by facilitating complex formation with phenanthrene compounds. Here, all three PET/CDP nanofibers demonstrated the ability to function as a molecular filter for water purification through complexation of the phenanthrene with CDP. As it mentioned in the previous section it is notable that the surface area, average pore diameter and cumulative pore volume of nanofibers were decreased after CDP modification. However, the molecular filtration efficiency was still further improved for PET/CDP nanofibers compared to pristine PET nanofibers due to the CDP structure onto nanofibers, which plays a crucial role in molecular capturing of phenanthrene. When the $\mathrm{CD}$ types were

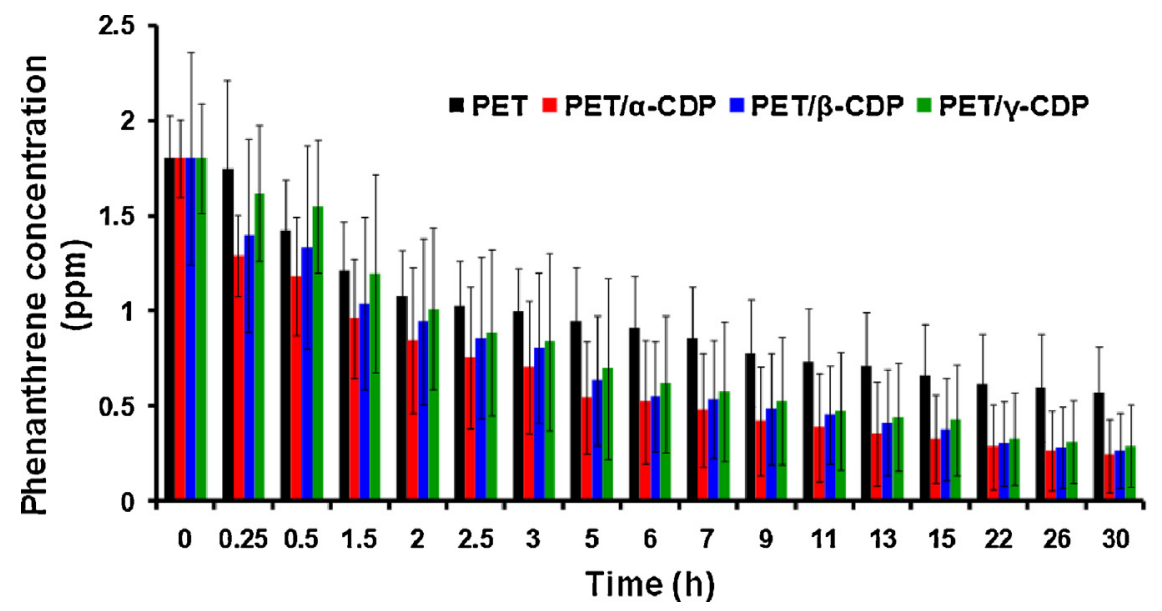

Fig. 6. Time-dependent decrease of phenanthrene concentration in the aqueous solution containing nanofibrous mats. 

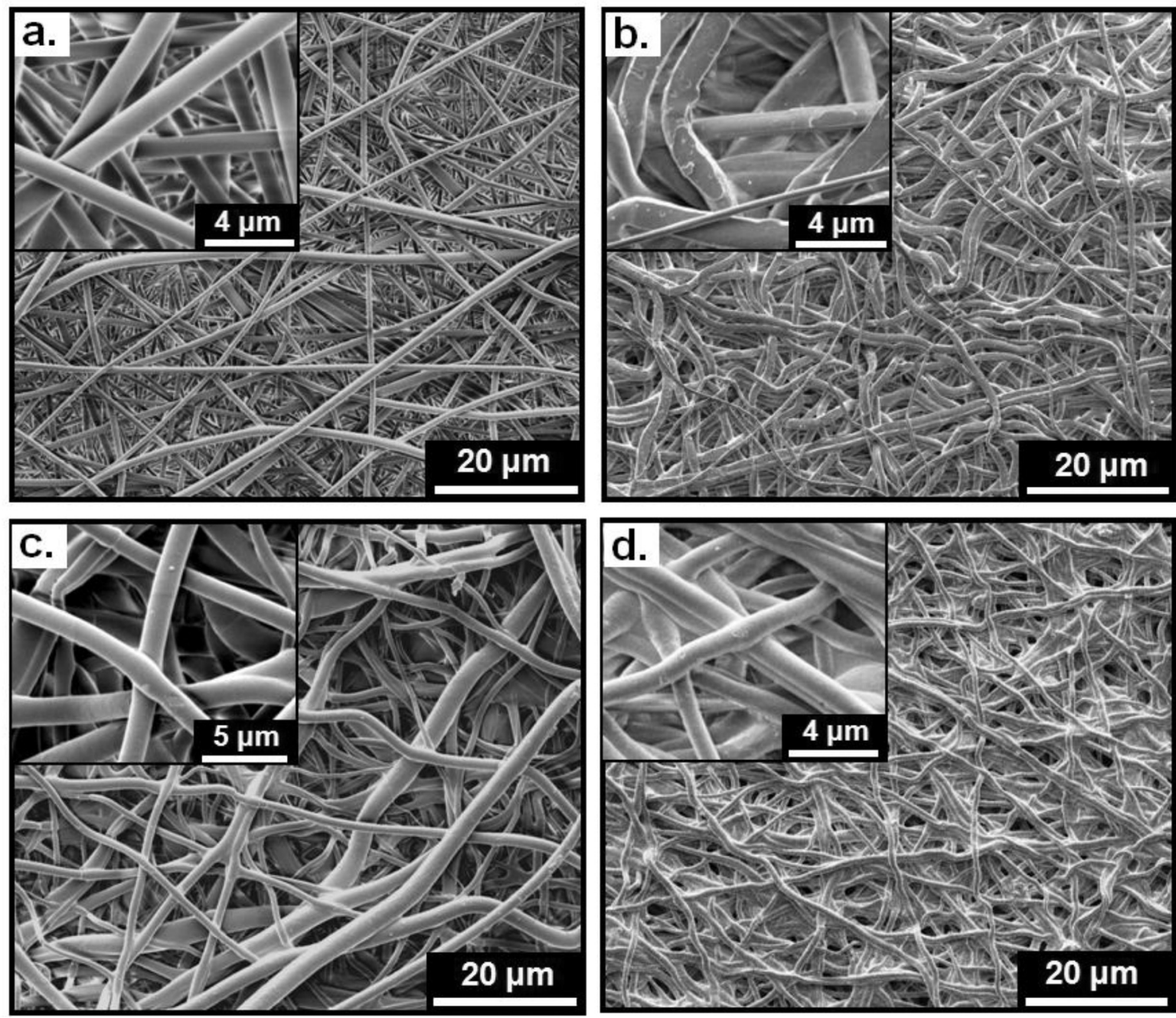

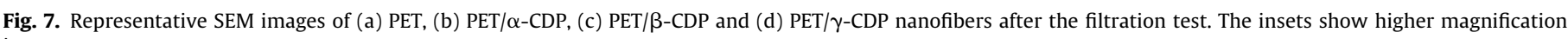
images.

compared, all three PET/CDP samples showed approximately same filtration efficiency for the removal of phenanthrene at the end of filtration test. Although TGA suggested that the amount of CDP coating onto PET nanofibers was on the order of $\beta-C D P>\gamma-C D P>\alpha-C D P$, it is likely that not all the $\mathrm{CD}$ molecules are available for complexation. So, the three PET/CDP samples may have comparable amount of $\mathrm{CD}$ cavity available for complexation. Even so, the average percentage removal of phenanthrene with respect to initial time was slightly better for PET $/ \alpha-C D P$ and this is possibly because of the higher surface area of PET $/ \alpha-C D P$ nanoweb compared to PET $/ \beta-C D P$ and PET $/ \gamma$-CDP nanowebs. We have also inspected the dimension stability of the PET and PET/CDP nanofibers, and we observed that the mats kept their nanofibrous structure after the filtration test (Fig. 7). In short, the surface modification of electrospun PET nanofibers with CDP enhanced the efficiency of its filtration performance by facilitating complex formation with organic compounds such as phenanthrene.

\section{Conclusion}

In this study, we have achieved the surface modification of electrospun PET nanofibers with CDP. First, PET nanofibers were obtained via electrospinning, then, water-insoluble crosslinked CDP coating was formed onto PET nanofibers by polymerization reaction between $\mathrm{CD}$ and crosslinking agent (citric acid). For a comparative study, three different types of CD: $\alpha-C D, \beta-C D$ and $\gamma-$ $C D$ were used to form CDP onto electrospun PET nanofibers. The imaging analysis by SEM revealed that nanofibrous structure of the PET nanofibers was preserved after surface modification with CDP. Yet, the surface of the PET/CDP nanofibers was rough/irregular, whereas that of unmodified PET nanofibers was smooth. Moreover the diameter of the PET nanofibers increased after CDP modification possibly due to the presence of CDP layer onto nanofibers and/or swelling of the nanofibers during modification process. BET measurements indicated that the surface area of the PET/CDP nanofibers was decreased due to the presence of CDP coating compared to pristine PET nanofibers. The presence of CDP coating on the surface of PET nanofibers was supported by XPS analyses. The thermal analysis of PET/CDP nanofibers carried out by TGA showed two main thermal degradation steps corresponding to CDP and PET degradation. The modification of PET nanofibers with CDP resulted in slightly higher thermal stability, and the char yield was higher for PET/CDP nanofibers compared to unmodified PET nanofibers. The TGA data also indicated that the amount of CDP coating onto PET nanofibers was on the order of $\beta-\mathrm{CDP}>\gamma-\mathrm{CDP}>\alpha$-CDP. DMA results elucidated the improvement of mechanical properties for PET/CDP nanofibers, that is, PET/CDP nanofibers have shown higher storage modulus and higher glass transition temperature compared to unmodified PET nanofibers. The filtration performance of the CDP surface modified PET nanofibers was tested by removal of the 
polycyclic aromatic hydrocarbon waste molecule (phenanthrene) from its aqueous solution. Although the surface area of the PET/CDP were less, we observed that PET/CDP nanofibers have shown better filtration efficiency when compared to the pristine PET nanofibers due to the inclusion complexation capability of CDP onto PET nanofibers. Initially, the average percentage removal of phenanthrene with respect to time was slightly better for PET $/ \alpha-C D P$, but at the end of filtration test the all PET/CDP samples showed more or less same filtration efficiency for the removal of phenanthrene from the aqueous solution. It was also observed that PET/CDP mats have kept their nanofibrous structure after the filtration test. In brief, our results indicated that PET/CDP nanofibers have shown the potentials to be used as a filter/membrane for water purification owing to very high surface area of electrospun nanofibers and surface associated CDP, since CD molecules have inclusion complexation capability with polycyclic aromatic hydrocarbons and other types of organic waste molecules.

\section{Acknowledgements}

State Planning Organization (DPT) of Turkey is acknowledged for the support of UNAM-Institute of Materials Science \& Nanotechnology. Dr. T. Uyar acknowledges TUBITAK-The Scientific and Technological Research Council of Turkey for funding project \#110M612 and EU FP7-PEOPLE-2009-RG Marie Curie-IRG for funding NANOWEB (PIRG06-GA-2009-256428). F. Kayaci acknowledges TUBITAK-BIDEB for the national Ph.D. study scholarship.

\section{References}

[1] Y. Dai, J. Niu, L. Yin, J. Xu, Y. Xi, Sorption of polycyclic aromatic hydrocarbons on electrospun nanofibrous membranes: sorption kinetics and mechanism, Journal of Hazardous Materials 192 (2011) 1409-1417.

[2] R.S. Barhate, S. Ramakrishna, Nanofibrous filtering media: filtration problems and solutions from tiny materials, Journal of Membrane Science 296 (2007) $1-8$.

[3] K. Yoon, B.S. Hsiao, B. Chu, Functional nanofibers for environmental applications, Journal of Materials Chemistry 18 (2008) 5326-5334.

[4] T. Uyar, R. Havelund, Y. Nur, A. Balan, J. Hacaloglu, L. Toppare, F. Besenbacher, P. Kingshott, Cyclodextrin functionalized poly(methyl methacrylate)(PMMA) electrospun nanofibers for organic vapors waste treatment, Journal of Membrane Science 365 (2010) 409-417.

[5] E. Scholten, L. Bromberg, G.C. Rutledge, T.A. Hatton, Electrospun polyurethane fibers for absorption of volatile organic compounds from air, ACS Applied Materials \& Interfaces 3 (2011) 3902-3909.

[6] S. Subramanian, S. Ramakrishna, New directions in nanofiltration applications are nanofibers the right materials as membranes in desalination? Desalination 308 (2013) 198-208.

[7] P.K. Neghlani, M. Rafizadeh, F.A. Taromi, Preparation of aminatedpolyacrylonitrile nanofiber membranes for the adsorption of metal ions: comparison with microfibers, Journal of Hazardous Materials 186 (2011) 182-189.

[8] J. Niu, J. Xu, Y. Dai, J. Xu, H. Guo, K. Sun, R. Liu, Immobilization of horseradish peroxidase by electrospun fibrous membranes for adsorption and degradation of pentachlorophenol in water, Journal of Hazardous Materials 246/247 (2013) $119-125$

[9] J. Szejtli, Introduction and general overview of cyclodextrin chemistry, Chemical Reviews 98 (1998) 1743-1754.

[10] A. Hedges, Industrial applications of cyclodextrins, Chemical Reviews 98 (1998) 2035-2044.

[11] E.M. Del Valle, Cyclodextrins and their uses: a review, Process Biochemistry 39 (2004) 1033-1046.

[12] T. Badr, K. Hanna, C. De Brauer, Enhanced solubilization and removal of naphthalene and phenanthrene by cyclodextrins from two contaminated soils, Journal of Hazardous Materials 112 (2004) 215-223.

[13] N. Morin-Crini, G. Crini, Environmental applications of water-insoluble $\beta$ cyclodextrin-epichlorohydrin polymers, Progress in Polymer Science 38 (2013) 344-368.

[14] M.V. Rekharsky, Y. Inoue, Complexation thermodynamics of cyclodextrins, Chemical Reviews 98 (1998) 1875-1918.

[15] R. Romi, P.L. Nostro, E. Bocci, F. Ridi, P. Baglioni, Bioengineering of a cellulosic fabric for insecticide delivery via grafted cyclodextrin, Biotechnology Progress 21 (2008) 1724-1730.

[16] P.L. Nostro, L. Fratoni, F. Ridi, P. Baglioni, Surface treatments on Tencel fabric: grafting with $\beta$-cyclodextrin, Journal of Applied Polymer Science 88 (2003) 706-715.
[17] E.S. Abdel-Halim, M.M.G. Fouda, I. Hamdy, F.A. Abdel-Mohdy, S.M. El-Sawy Incorporation of chlorohexidin diacetate into cotton fabrics grafted with glycidyl methacrylate and cyclodextrin, Carbohydrate Polymers 79 (2010) 47-55, 3.

[18] B. Martel, P. Le Thuaut, S. Bertini, G. Crini, M. Bacquet, G. Torri, M. Morcellet, Grafting of cyclodextrins onto polypropylene nonwoven fabrics for the manufacture of reactive filters. III. Study of the sorption properties, Journal of Applied Polymer Science 85 (2002) 1771-1778.

[19] L. Ducoroy, B. Martel, B. Bacquet, M. Morcellet, Ion exchange textiles from the finishing of PET fabrics with cyclodextrins and citric acid for the sorption of metallic cations in water, Journal of Inclusion Phenomena and Macrocyclic Chemistry 57 (2007) 271-277

[20] N. Blanchemain, T. Laurent, S. Haulon, M. Traisnel, C. Neut, J. Kirkpatrick, M. Morcellet, H.F. Hildebrand, B. Martel, In vitro study of a HP gamma-cyclodextrin grafted PET vascular prosthesis for application as anti-infectious drug delivery system, Journal of Inclusion Phenomena and Macrocyclic Chemistry 57 (2007) 675-681.

[21] N. Blanchemain, S. Haulon, E. Marcon-Bachari, M. Traisnel, C. Neut, J. Kirkpatrick, M. Morcellet, H. Hildebrand, B. Martel, Vascular prostheses with controlled release of antibiotics. Part 1. Surface modification with cyclodextrins of PET prostheses, Biomolecular Engineering 24 (2007) 149-153.

[22] T. Uyar, R. Havelund, J. Hacaloglu, F. Besenbacher, P. Kingshott, Functional electrospun polystyrene nanofibers incorporating $\alpha$-, $\beta$-, and $\gamma$-cyclodextrins: comparison of molecular filter performance, ACS Nano 4 (2010) 5121-5130.

[23] T. Uyar, R. Havelund, Y. Nur, J. Hacaloglu, F. Besenbacher, P. Kingshott, Molecular filters based on cyclodextrin functionalized electrospun fibers, Journal of Membrane Science 332 (2009) 129-137.

[24] B. Martel, M. Morcellet, D. Ruffin, L. Ducoroy, M. Weltrowski, Finishing of polyester fabrics with cyclodextrins and polycarboxylic acids as crosslinking agents, Journal of Inclusion Phenomena and Macrocyclic Chemistry 44 (2002) 443-446.

[25] B. Martel, D. Ruffin, M. Weltrowski, Y. Lekchiri, M. Morcellet, Water-soluble polymers and gels from the polycondensation between cyclodextrins and poly (carboxylic acid)s: a study of the preparation parameters, Journal of Applied Polymer Science 97 (2005) 433-442.

[26] S. Bednarz, M. Lukasiewicz, W. Mazela, M. Pajda, W. Kasprzyk, Chemical structure of poly( $\beta$-cyclodextrin-co-citric acid), Journal of Applied Polymer Science 119 (2011) 3511-3520.

[27] D. Zhao, L. Zhao, C. Zhu, Z. Tian, X. Shen, Synthesis and properties of waterinsoluble $\beta$-cyclodextrin polymer crosslinked by citric acid with PEG-400 as modifier, Carbohydrate Polymers 78 (2009) 125-130.

[28] D. Zhao, L. Zhao, C.-S. Zhu, W.-O. Huang, J.-L. Hu, Water-insoluble $\beta$ cyclodextrin polymer crosslinked by citric acid: synthesis and adsorption properties toward phenol and methylene blue, Journal of Inclusion Phenomena and Macrocyclic Chemistry 63 (2009) 195-201.

[29] Y. El Ghoul, B. Martel, A. El Achari, C. Campagne, L. Razafimahefa, I. Vroman, Improved dyeability of polypropylene fabrics finished with $\beta$ cyclodextrin-citric acid polymer, Polymer Journal 42 (2010) 804-811

[30] A. Hebeish, A. El Shafei, S. Shaarawy, Synthesis and characterization of multifunctional cotton containing cyclodextrin and butylacrylate moieties, Polymer-Plastics Technology and Engineering 48 (2009) 839-850.

[31] N. Hayes, G. Beamson, D. Clark, D.L. Law, R. Raval, Crystallisation of PET from the amorphous state: observation of different rates for surface and bulk using XPS and FTIR, Surface and Interface Analysis 24 (1998) 723-728.

[32] S.B. Amor, M. Jacquet, P. Fioux, M. Nardin, AZnO/PET assembly study: optimization and investigation of the interface region, Materials Chemistry and Physics 119 (2010) 158-168

[33] S.B. Amor, M. Jacquet, P. Fioux, M. Nardin, XPS characterisation of plasma treated and zinc oxide coated PET, Applied Surface Science 255 (2009) 5052-5061.

[34] M. Bou, J. Martin, T. Le Mogne, L. Vovelle, Chemistry of the interface between aluminium and polyethyleneterephthalate by XPS, Applied Surface Science 47 (1991) 149-161.

[35] A. Ektessabi, K. Yamaguchi, Changes in chemical states of PET films due to low and high energy oxygen ion beam, Thin Solid Films 377 (2000) 793-797.

[36] E. Uchida, H. Iwata, Y. Ikada, Surface structure of poly (ethylene terephthalate) film grafted with poly (methacrylic acid), Polymer 41 (2000) 3609-3614.

[37] F. Kayaci, T. Uyar, Electrospinning of zein nanofibers incorporating cyclodextrins, Carbohydrate Polymers 90 (2012) 558-568.

[38] S. Gawish, A. Ramadan, S. Mosleh, M. Morcellet, B. Martel, Synthesis and characterization of novel biocidal cyclodextrin inclusion complexes grafted onto polyamide- 6 fabric by a redox method, Journal of Applied Polymer Science 99 (2005) 2586-2593.

[39] I. Shown, C. Murthy, Grafting of cotton fiber by water-soluble cyclodextrinbased polymer, Journal of Applied Polymer Science 111 (2009) 2056-2061.

[40] F. Huang, Q. Wei, Y. Cai, N. Wu, Surface structures and contact angles of electrospun poly (vinylidene fluoride) nanofiber membranes, International Journal of Polymer Analysis and Characterization 13 (2008) 292-301.

[41] G. Chalumot, C. Yao, V. Pino, J.L. Anderson, Determining the stoichiometry and binding constants of inclusion complexes formed between aromatic compounds and $\beta$-cyclodextrin by solid-phase microextraction coupled to high-performance liquid chromatography, Journal of Chromatography A 1216 (2009) 5242-5248

[42] J. Gomez, M.T. Alcantara, M. Pazos, M.A. Sanroman, Soil washing using cyclodextrins and their recovery by application of electrochemical technology, Chemical Engineering Journal 159 (2010) 53-57. 